\title{
OBLICZENIA I DOBÓR GRUNTOWEGO WYMIENNIKA CIEPLA DLA POMPY CIEPŁA
}

\begin{abstract}
W artykule przedstawiono rozwój rynku pomp ciepła w Polsce w latach 20102013. Dokonano analizy gruntu jako dolnego źródła ciepła dla pomp ciepła. Przedstawiono sposób doboru długości rur wymiennika ciepła stanowiącego ujęcie dolnego źródła ciepła dla pomp ciepła, wykorzystując wytyczne przedstawione przez Polską Organizację Rozwoju i Technologii Pomp Ciepła. Następnie przedstawiono algorytm wyznaczania gęstości strumienia ciepła i doboru długości rur wymiennika oraz porównano otrzymane wyniki obliczeń. Wyznaczanie ilości energii jaką można pozyskać z gruntu jest trudnym zagadnieniem. Aby otrzymać dokładne wyniki należy dla każdego przypadku sprawdzić rodzaj podłoża, w którym jest układany wymiennik ciepła. Rodzaj gruntu, z którego czerpana jest energia ma ogromne znaczenie dla doboru oraz projektowania dolnego źródła ciepła. Zawartość wilgoci w gruncie wpływa na współczynnik przewodzenia ciepła gruntu oraz ilość pobieranej energii. Wytyczne dotyczące wyznaczania długości rur poziomego wymiennika ciepła, opublikowane przez PORT PC mogą służyć do wstępnego oraz szybkiego doboru długości rur. Otrzymany wynik obarczony jest pewnym błędem, ze względu na zakładaną wartość gęstości strumienia ciepła. Określenie rodzaju gruntu jest zasadne. Pozwala dokładnie obliczyć jednostkowa gęstość strumienia ciepła pobieraną z gruntu oraz dobrać odpowiednią długość rur wymiennika niezależnie od zastosowanej metody.
\end{abstract}

Słowa kluczowe: dolne źródło pompy ciepła, pompa ciepła glikol/woda, poziomy, gruntowy wymiennik ciepła,

\section{Wstęp}

Na całym świecie można zauważyć stały rozwój cywilizacyjny. Niektóre kraje rozwijają się w szybszym tempie, inne wolniej. W każdym razie postęp gospodarczy $\mathrm{i}$ wzrost liczby ludności wiąże się ze wzrostem zapotrzebowania na energię potrzebną do zapewnienia komfortu ludzi. Podobnie dzieje się w Polsce. Wzrost cen naturalnych surowców, które wykorzystuje się do wytwarzania energii elektrycznej i cieplnej powoduje wzrost kosztów ogrzewania budynków. Surowce naturalne kiedyś ulegną wyczerpaniu, dlatego też zaleca

\footnotetext{
${ }^{1}$ Autor do korespondencji/coresponding author: Piotr Kopeć, Politechnika Krakowska, 31-864 Kraków, al. Jana Pawła II 37, tel. (12) 62834 69, pkopec@ mech.pk.edu.pl
} 
się wykorzystywać wszelkiego rodzaju energię odnawialną. Dodatkowo spełnianie coraz to większych wymogów formalnych, mających na celu ochronę środowiska powoduje, że coraz częściej zwraca się uwagę na korzystanie ze źródeł odnawialnych. Budownictwo energooszczędne oraz pasywne zarówno dla budynków jednorodzinnych, jak i wielorodzinnych również wymaga wykorzystania odnawialnych źródeł energii na pokrycie zapotrzebowania budynku na ciepło i ciepłą wodę użytkową. Pewnego rodzaju zachętą do stosowania odnawialnych źródeł energii w budownictwie są dopłaty z ministerstwa środowiska lub kredyty inwestycyjne na preferencyjnych warunkach.

Pompa ciepła jest jednym z urządzeń, które korzysta z energii odnawialnej. Jej głównym zadaniem jest wykorzystanie niskotemperaturowej energii cieplnej z odnawialnych źródeł energii i przetransportowanie jej na wyższy poziom energetyczny, do wytworzenia ciepła o wyższej temperaturze, przy wykorzystaniu zewnętrznej energii: mechanicznej, cieplnej lub elektrycznej [5]. Pompa ciepła może pobierać energię $\mathrm{z}$ różnych rodzajów źródeł niskotemperaturowych. $\mathrm{Z}$ tego też względu klasyfikuje się je na pompy ciepła: powietrzne, gruntowe (poziome, pionowe) i wodne.

Rynek pomp ciepła w Polsce systematycznie rośnie. Średnio około 20\% rocznie. Opierając się na badaniach i danych Polskiej Organizacji Rozwoju Technologii Pomp Ciepła (PORT PC) na rysunku 1 przedstawiono sprzedaż pomp ciepła w Polsce w latach 2010-2013 [2].

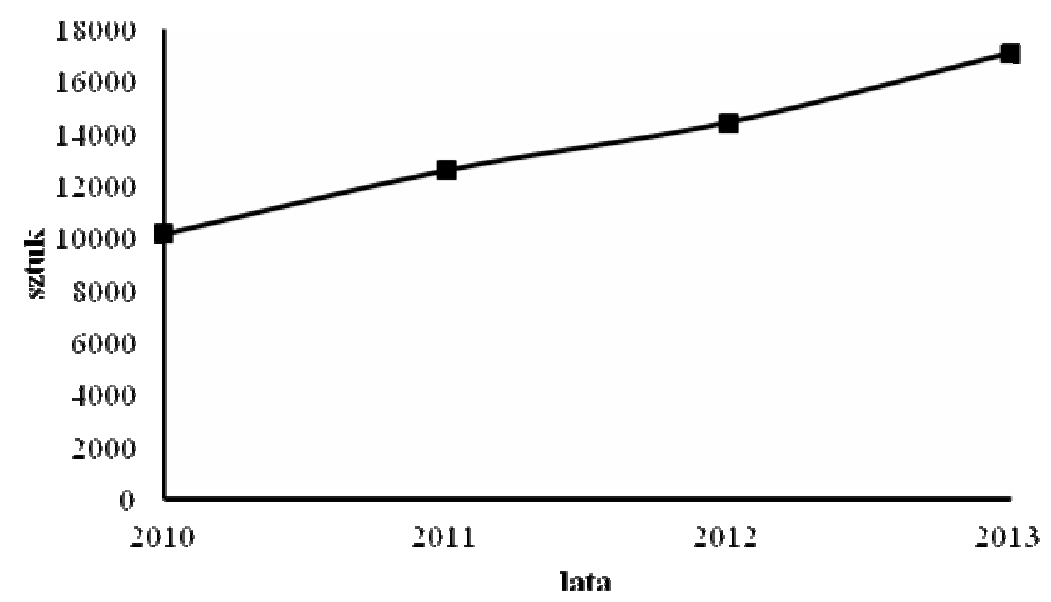

Rys. 1. Sprzedaż pomp ciepła w Polsce w latach 2010-2013, na podstawie [2]

Fig. 1. Sales of heat pumps in Poland in years 2010-2013, based on [2]

Udział gruntowych pomp ciepła (solanka/woda) wynosi średnio 32\% ogólnego rynku i jest największy spośród pomp ciepła przeznaczonych do zaspoko- 
jenia wymaganego zapotrzebowania na energię dla budynku. Większą sprzedaż mają jedynie pompy ciepła powietrze/woda, ale są one przeznaczone tylko i wyłącznie do podgrzewania C.W.U, natomiast do pokrycia strat cieplnych budynku wykorzystywane jest inne źródło energii.

\section{Grunt jako dolne źródło ciepła}

\subsection{Charakterystyka gruntu}

Gruntowe dolne źródło dla pompy ciepła jest w pewnym sensie zbiornikiem zakumulowanej energii słonecznej i geotermalnej, wykorzystywanej do odparowania ciekłego czynnika krążącego w instalacji pompy ciepła. Aby odpowiednio dobrać dolne źródło ciepła należy sprawdzić, czy charakteryzuje się kilkoma ważnymi cechami. Do właściwości, jakie powinno posiadać dolne źródło ciepła należą [5]:

- łatwa dostępność,

- duża pojemność cieplna,

- wysoka i stała temperatura,

- niskie koszty inwestycyjne i eksploatacyjne,

- mała korozyjność,

- dobra koherentność.

Temperatura dolnego źródła ciepła ma duży wpływ na efektywność pracy pompy ciepła. Im ta temperatura jest wyższa, a dokładniej im mniejsza różnica temperatur pomiędzy dolnym i górnym źródłem ciepła, tym większa jest efektywność pracy pompy ciepła. Wzrasta wówczas wartość współczynnika COP pompy ciepła.

Grunt posiada większość cech, jakie powinno mieć dolne źródło ciepła. Jest ogólnodostępny, ma dużą pojemność cieplną, posiada stosunkowo wysoką i stałą temperaturę $w$ głębszych warstwach gruntu, cechuje się niskimi kosztami eksploatacyjnymi. Korozyjność nie ma większego znaczenia, gdyż wymienniki najczęściej wykonane są z rur polietylenowych. W górnych warstwach do około, $10 \mathrm{~m}$ głębokości, zakumulowana energia pochodzi głównie z promieniowania słonecznego oraz wymiany ciepła i masy z atmosferą. Wartość temperatury na tej głębokości gruntu jest stała i zbliżona jest do średniej rocznej temperatury powietrza. W niższych warstwach, a więc poniżej $10 \mathrm{~m}$, akumulowane jest ciepło, które pochodzi zarówno z promieniowania słonecznego, jak i z przewodzenia ciepła $z$ wnętrza Ziemi [4]. Na rysunku 2 przedstawiono wykres obrazujący zmianę temperatury gruntu w strefie klimatu umiarkowanego. 


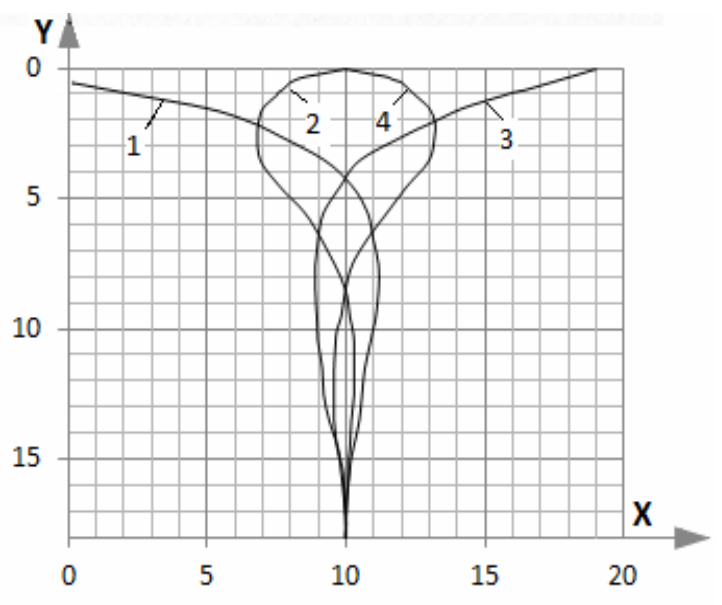

Rys. 2. Rozkład temperatury gruntu w strefie klimatu umiarkowanego, na podstawie [4] $\mathrm{X}$ - temperatura $\left[{ }^{\circ} \mathrm{C}\right], \mathrm{Y}$ - głębokość $[\mathrm{m}], 1-1$ lutego, 2 - 1 maja, 3 - 1 sierpnia, 4 - 1 listopada

Fig. 2. Ground temperature profile in temperate climate, based on [4]

$\mathrm{X}$ - temperature $\left[{ }^{\circ} \mathrm{C}\right], \mathrm{Y}$ - depth $[\mathrm{m}], 1-1$ February , 2 - 1 May, 3 - 1 August, 4 - 1 November

Na rozkład temperatury w gruncie wpływa kilka czynników. Jednym $\mathrm{z}$ nich jest oddziaływanie klimatu, a więc: opadów, temperatury powietrza, wiatru i promieniowania słonecznego. Kolejny element, który wpływa na temperaturę gruntu to rodzaj wierzchniego pokrycia [3]. Następny element to struktura i wilgotność. Im więcej wilgoci zawiera grunt, tym jest bardziej przydatny jako źródło ciepła. W zależności od zawartości wilgoci i rodzaju gruntu przyjmuje się, że z $1 \mathrm{~m}^{2}$ powierzchni można uzyskać strumień energii o wartości $10 \div 50 \mathrm{~W}$, natomiast dla wymienników pionowych z $1 \mathrm{mb}$ rury można uzyskać strumień energii od 25 do $70 \mathrm{~W}$ [5].

\subsection{Obliczenia i dobór poziomego wymiennika ciepła}

W związku z rozwojem oraz coraz większą liczbą montowanych pomp ciepła w naszym kraju, Polska Organizacja Rozwoju i Technologii Pomp Ciepła wydała w październiku 2013 „Wytyczne projektowania, wykonania i odbioru instalacji z pompami ciepła cz.1". Głównym celem publikacji było zebranie oraz uporządkowanie informacji dotyczących pomp ciepła współpracujących z gruntowymi wymiennikami ciepła, aby poprawnie zaprojektować, wykonać oraz dokonać odbioru wykonanej instalacji. Opierając się na informacjach zawartych w wytycznych opublikowanych przez PORT PC, przy doborze pompy ciepła, której moc nie przekracza $30 \mathrm{~kW}$ oraz przy braku informacji co do rodzaju gruntu, należy przyjmować jednostkową wydajność cieplną $\dot{q}_{H}$, jaką można pozyskać z gruntu, nie większą jednak niż $20 \mathrm{~W} / \mathrm{m}^{2}$. Na tej podstawie można wyznaczyć długość rur poziomego wymiennika [1]. 
Do obliczeń założono następujące dane i parametry zawarte w tabeli 1.

Tabela 1. Dane do obliczeń

Table 1. Calculation data

\begin{tabular}{|l|c|l|c|}
\hline $\begin{array}{l}\dot{Q}_{c}-\text { zapotrzebowanie na } \\
\text { moc cieplną PC }\end{array}$ & $10 \mathrm{~kW}$ & $\begin{array}{l}\mathrm{t}_{\mathrm{gz}} \text { - temperatura zasilania } \\
\text { ogrzewania }\end{array}$ & $35{ }^{\circ} \mathrm{C}$ \\
\hline COP $(\mathrm{B} 0 / \mathrm{W} 35)$ & 4 & $\begin{array}{l}\mathrm{t}_{\mathrm{gp}} \text { - temperatura powrotu } \\
\text { ogrzewania }\end{array}$ & $30{ }^{\circ} \mathrm{C}$ \\
\hline $\begin{array}{l}\hat{q}_{H} \text { - jednostkowa wydaj- } \\
\text { nośc cieplna }\end{array}$ & $\begin{array}{c}20 \\
\mathrm{~W} / \mathrm{m}^{2}\end{array}$ & $\begin{array}{l}\mathrm{e}_{\mathrm{p}} \text { - podziałka układu rur } \\
\text { wymiennika }\end{array}$ & $0,8 \mathrm{~m}$ \\
\hline
\end{tabular}

Aby wyznaczyć moc, jaką powinno dysponować dolne źródło ciepła Q̊ skorzystać z wzoru (1).

$$
\dot{Q}_{O}=\dot{Q}_{C} \frac{C O P-1}{C O P}
$$

gdzie: $\dot{Q}_{C}-$ zapotrzebowanie na moc cieplną pompy ciepła, straty cieplne budynku [kW], COP - współczynnik efektywności pompy ciepła [-],

Łączną obliczeniową powierzchnię poziomego wymiennika ciepła $\mathrm{A}_{\mathrm{O}}$ wyliczono zgodnie z wytycznymi [1] ze wzoru (2).

$$
A_{O}=\frac{\dot{Q}_{O}}{\dot{q}_{H}}
$$

gdzie: $\dot{q}_{H}$ - jednostkowa wydajność cieplna $\left[\mathrm{W} / \mathrm{m}^{2}\right]$

Łączną długość rur poziomego wymiennika ciepła $L_{p}$ wyliczono ze wzoru (3)

$$
L_{p}=\frac{A_{O}}{e_{p}}
$$

gdzie: $e_{p}$ - rozstawienie rur wymiennika $[\mathrm{m}]$

Otrzymane wyniki z obliczeń przedstawia tabela 2 
Tabela 2. Wyniki obliczeń

Table 2. Calculation results

\begin{tabular}{|c|c|c|}
\hline$\dot{Q}_{O}[\mathrm{~W}]$ & $\mathrm{A}_{\mathrm{O}}\left[\mathrm{m}^{2}\right]$ & $L_{p}[\mathrm{~m}]$ \\
\hline 7500 & 375 & 468,75 \\
\hline
\end{tabular}

Wymiennik poziomy należy wykonać w minimum dwóch pętlach [1]. Natomiast długość jednej pętli powinna zawierać się w przedziale $100 \div 150 \mathrm{~m}$ [5]. Odnośnie otrzymanego wyniku z przykładu obliczeniowego można wykonać wymiennik w postaci 4 pętli, z których każda będzie miała długość $\mathrm{l}=120 \mathrm{~m}$.

Taki sposób obliczania niesie ze sobą pewne niebezpieczeństwo. Długość poziomego wymiennika jest wyznaczona tylko przy założonej wartości $\dot{q}_{H}$ $i$ jest to wynik przybliżony. Zmiana jednostkowej wydajności cieplnej gruntu będzie powodowała zmianę długości wymiennika. $Z$ tego też względu zaleca się wykonanie badań gruntu, aby móc określić wydajność dolnego źródła ciepła. Poniżej przedstawiono przykład obliczeniowy, w którym wyznaczono długość poziomego wymiennika, przy wyznaczeniu jednostkowej wydajności cieplnej $\hat{q}_{H}$, wykorzystując dostępne wzory obliczeniowe, przedstawione w pracy [5].

Gęstość strumienia ciepła odniesiona do $1 \mathrm{mb}$ rury obliczono korzystając $\mathrm{z}$ wzorów (4)-(8). Sposób umiejscowienia rury wymiennika w gruncie oraz schemat układu przyjętego do obliczeń przedstawiono na rysunku 3.

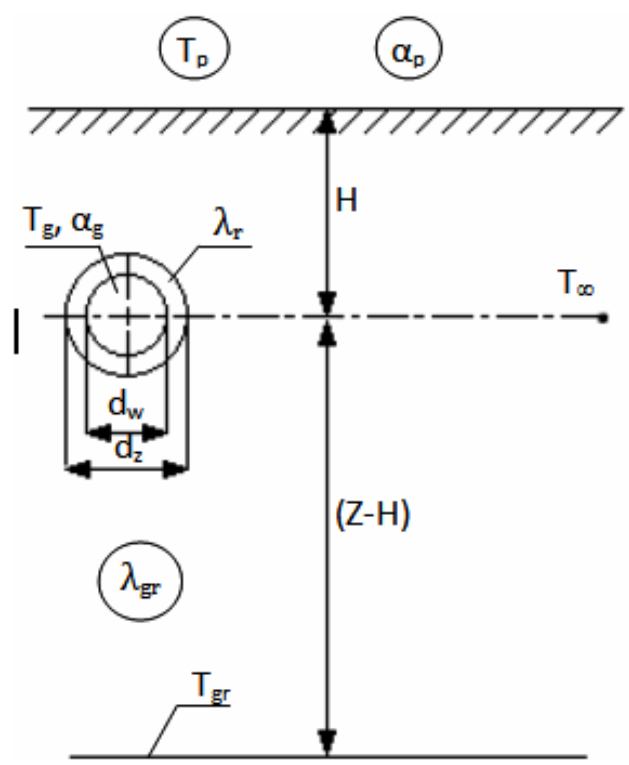

Rys. 3. Przykład rozmieszczenia rury wymiennika w gruncie, na podstawie [5]

Fig. 3. Sample arrangement of the heat exchanger pipe in the ground, based on [5] 


$$
\begin{aligned}
& \dot{q}_{L}=\lambda_{g r} \Delta T \frac{2 \pi}{\ln \left(K+\sqrt{K^{2}-1}\right)} \\
& \Delta T=T_{p}-T_{g m}+B\left(T_{g r}-T_{p}\right) \\
& B=\frac{H}{Z} \\
& K=\frac{1}{\pi} \exp \left[C+\frac{\pi^{2}}{4} \exp (-2 C)\right] \sin (\pi B) \\
& C=\frac{2 \lambda_{g r}}{\alpha_{g} d_{w}}+\frac{\lambda_{g r}}{\lambda_{r}} \ln \left(\frac{d_{z}}{d_{w}}\right)+\ln \left[\frac{2 \lambda_{g r}}{d_{z}}\left(\frac{1}{\alpha_{p}}+\frac{Z}{\lambda_{g r}}\right)\right]
\end{aligned}
$$

gdzie: $\dot{q}_{L}$ - jednostkowy strumień ciepła $[\mathrm{W} / \mathrm{m}]$,

$\alpha_{\mathrm{g}}$ - współczynnik przejmowania ciepła od strony glikolu [W/( $\left.\left.\mathrm{m}^{2} \mathrm{~K}\right)\right]$,

$\alpha_{\mathrm{p}}$ - współczynnik przejmowania ciepła od strony powietrza [W/( $\left.\left.\mathrm{m}^{2} \mathrm{~K}\right)\right]$,

$\lambda_{\mathrm{gr}}-$ współczynnik przewodzenia ciepła gruntu $[\mathrm{W} /(\mathrm{mK})]$,

$\lambda_{\mathrm{r}}-$ współczynnik przewodzenia ciepła rury [W/(mK)],

$\mathrm{d}_{\mathrm{w}}-$ średnica wewnętrzna rury $[\mathrm{m}]$

$\mathrm{d}_{\mathrm{z}}$ - średnica zewnętrzna rury $[\mathrm{m}]$

$\mathrm{T}_{\mathrm{gr}}-$ temperatura gruntu $\left[{ }^{\circ} \mathrm{C}\right]$

$\mathrm{T}_{\mathrm{gm}}$ - temperatura średnia $33 \%$ roztworu wody i glikolu $\left[{ }^{\circ} \mathrm{C}\right]$

$\mathrm{T}_{\mathrm{p}}$ - temperatura powietrza przy gruncie $\left[{ }^{\circ} \mathrm{C}\right]$

$\mathrm{H}$ - głębokość umieszczenia wymiennika gruntowego [m]

$\mathrm{Z}$ - głębokość, na której temperatura gruntu jest stała [m]

\begin{tabular}{|c|c|c|c|c|c|}
\hline $\begin{array}{c}\alpha_{\mathrm{g}} \\
{\left[\mathrm{W} /\left(\mathrm{m}^{2} \mathrm{~K}\right)\right]}\end{array}$ & $\begin{array}{c}\alpha_{\mathrm{p}} \\
{\left[\mathrm{W} /\left(\mathrm{m}^{2} \mathrm{~K}\right)\right]}\end{array}$ & $\begin{array}{c}\lambda_{\mathrm{gr}} \\
{[\mathrm{W} /(\mathrm{mK})]}\end{array}$ & $\begin{array}{c}\lambda_{\mathrm{r}} \\
{[\mathrm{W} /(\mathrm{mK})]}\end{array}$ & $\begin{array}{c}\mathrm{d}_{\mathrm{w}} \\
{[\mathrm{m}]}\end{array}$ & $\begin{array}{c}\mathrm{d}_{\mathrm{z}} \\
{[\mathrm{m}]}\end{array}$ \\
\hline 3605 & 15 & 2,25 & 0,5 & 0,04 & 0,0326 \\
\hline $\mathrm{T}_{\mathrm{gr}}\left[{ }^{\circ} \mathrm{C}\right]$ & $\mathrm{T}_{\mathrm{gm}}\left[{ }^{\circ} \mathrm{C}\right]$ & $\mathrm{T}_{\mathrm{p}}\left[{ }^{\circ} \mathrm{C}\right]$ & $\mathrm{H}[\mathrm{m}]$ & $\mathrm{Z}[\mathrm{m}]$ & \\
\hline 8 & -3 & -5 & 1,5 & 3 & \\
\hline
\end{tabular}

Do poprawnego przeprowadzenia obliczeń należy wprowadzić dodatkowe dane, przedstawione $\mathrm{w}$ tabeli 3.

Tabela 3. Dodatkowe dane do obliczeń

Table 3. Additional calculation data 
Na podstawie otrzymanej wartości jednostkowego strumienia ciepła wyznaczonej z wzoru (4) oraz podziałki rozstawienia rur można wyliczyć gęstość strumienia ciepła $\dot{q}_{H}$ odniesioną do powierzchni, korzystając z wzoru (9). Następnie, zgodnie z wzorami (2) i (3) oblicza się powierzchnię oraz łączną długość rur poziomego gruntowego wymiennika ciepła. Wyniki przedstawiono w tabeli 4.

$$
\dot{q}_{H}=\frac{\dot{q}_{L}}{e_{p}}
$$

Tabela 4. Wyniki obliczeń wg wzorów (4)-(9)

Table 4. Calculation results for formulas (4)-(9)

\begin{tabular}{|c|c|c|c|c|c|c|c|}
\hline $\begin{array}{c}\Delta \mathrm{T} \\
{[\mathrm{K}]}\end{array}$ & $\mathrm{B}$ & $\mathrm{K}$ & $\mathrm{C}$ & $\begin{array}{c}\dot{q}_{L} \\
{[\mathrm{~W} / \mathrm{m}]}\end{array}$ & $\begin{array}{c}\dot{q}_{H} \\
{\left[\mathrm{~W} / \mathrm{m}^{2}\right]}\end{array}$ & $\begin{array}{c}\mathrm{A}_{\mathrm{o}} \\
{\left[\mathrm{m}^{2}\right]}\end{array}$ & $\begin{array}{c}\mathrm{L}_{\mathrm{P}} \\
{[\mathrm{m}]}\end{array}$ \\
\hline 5 & 0,5 & 117,71 & 5,91 & 12,45 & 15,56 & 482,0 & 602,5 \\
\hline
\end{tabular}

Pomiędzy wynikami otrzymanymi z wytycznych oraz wzorów obliczeniowych są duże rozbieżności. Różnica wynosi około $130 \mathrm{~m}$. Długość wymiennika wyliczona na podstawie dokładnych wzorów jest o około $28 \%$ większa. Wartość gęstości strumienia ciepła otrzymana z wzoru (9) wynosi około 16 $\left[\mathrm{W} / \mathrm{m}^{2}\right]$ i jest niższa od zalecanych przez PORT PC. Należy zaznaczyć, że w pierwszym przypadku do obliczeń długości wymiennika, wartość gęstości strumienia ciepła jest przyjmowana i nie powinna przekroczyć $20 \mathrm{~W} / \mathrm{m}^{2}$. Natomiast w drugim otrzymujemy dokładną wartość ze wzoru (9) i na tej podstawie wyliczamy długość rur. W związku z tym, nie można w sposób jednoznaczny porównywać wyników. Po podstawieniu otrzymanej dokładnej wartości gęstości strumienia ciepła do wzorów (2)-(3), łączna długość rur poziomego wymiennika ciepła $\mathrm{L}_{\mathrm{P}}$ według wytycznych PORT PC wynosi $586 \mathrm{~m}$. Różnica pomiędzy otrzymanymi wynikami nie przekracza $3 \%$. Znając rodzaj gruntu, wytyczne PORT PC pozwalają szybko i dość dokładnie dobrać długość rur wymiennika. Wartość gęstości ściśle zależy od rodzaju gruntu, w którym będzie umieszczany wymiennik. Im większa zawartość wilgoci w gruncie tym większy współczynnik przewodzenia ciepła gruntu $\lambda_{\mathrm{gr}}[\mathrm{W} /(\mathrm{mK})]$. Na rysunku 4 przedstawiono wpływ wartości współczynnika przewodzenia ciepła gruntu na wartość gęstości strumienia ciepła jaki można uzyskać korzystając z wzoru (4). 


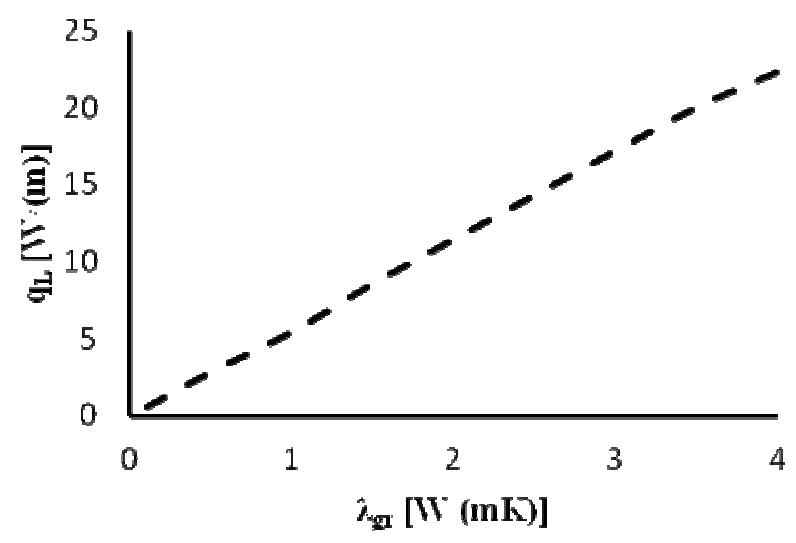

Rys. 4. Wpływ wartość współczynnika przewodzenia ciepła gruntu na gęstość strumienia ciepła

Fig. 4. Influence of ground thermal conductivity value on heat flux rate

\section{Podsumowanie}

Dobór oraz obliczenia gruntowego poziomego wymiennika ciepła dla pomp ciepła nie jest zagadnieniem łatwym. Każdy przypadek doboru należy potraktować indywidualnie. Ilość energii, jaką można uzyskać z $1 \mathrm{~m}^{2}$ gruntu lub $1 \mathrm{mb}$ rury jest wartością zmienną i zależną od kilku współczynników. Największy wpływ ma wartość współczynnika przewodzenia ciepła. Z kolei wartość współczynnika przewodzenia ciepła zależy od rodzaju gruntu oraz zawartej w nim wilgoci. Kolejne parametry, od których zależy ilość pozyskanej energii to głębokość, na której umieszczony jest wymiennik oraz temperatura gruntu na tej głębokości. Wiadomo również, że wraz z użytkowaniem pompy ciepła w okresie grzewczym grunt ulega wychłodzeniu. Jego regeneracja następuje w okresie letnim i jest zależna od promieniowania słonecznego oraz opadów atmosferycznych. Wytyczne, według których można obliczyć oraz dobrać wielkość wymiennika, podane przez PORT PC, mogą posłużyć do dość dobrego oraz szybkiego doboru wymiennika $\mathrm{w}$ celu dokonania wstępnej wyceny. Zgodnie z zaleceniami należy pamiętać, aby zakładana gęstość strumienia ciepła była nie większa niż $20 \mathrm{~W} / \mathrm{m}^{2}$. Aby wykonać dokładne wyliczenia długości rur należy określić rodzaj i wilgotność gruntu oraz wyznaczyć jednostkową wartość gęstości strumienia ciepła. Takie rozpoznanie gruntu również jest zalecane przez PORT PC, a w szczególności dla pomp ciepła, których moc $\geq 30 \mathrm{~kW}$. Posiadając dokładne informację na temat rodzaju gruntu błąd przy wyznaczaniu długości rur wymiennika przy stosowaniu zaprezentowanych metod nie przekracza 3\%. Brak dokładnych obliczeń może doprowadzić do doboru wymiennika ciepła o niewystarczających parametrach, a w konsekwencji do przechłodzenia gruntu oraz nie zapewnienia wystarczającej mocy grzewczej do pokrycia strat cieplnych budynku. 


\title{
Literatura
}

[1] Wytyczne projektowania, wykonania i odbioru instalacji z pompami ciepła, cz. 1, Dolne źródła do pomp ciepła, Polska Organizacja Rozwoju i Technologii Pomp Ciepła, wydanie I, Kraków 2013.

[2] Polski rynek pomp ciepła wzrósł o 20\% w 2013 r., Chłodnictwo \& Klimatyzacja, nr 4 (184), 2014, s. 34.

[3] Rubik M.: Pompy ciepła - poradnik, Ośrodek Informacji „Technika Instalacyjna w budownictwie", Warszawa 1999.

[4] Rubik M.: Pompy ciepła w systemie geotermii niskotemperaturowej, MULTICO Oficyna Wydawnicza, Warszawa 2011.

[5] Zalewski W.: Pompy ciepła sprężarkowe, sorpcyjne i termoelektryczne, IPPU Masta, Gdańsk 2001.

\section{CALCULATION AND SELECTION OF GROUND HEAT EXCHANGER FOR A HEAT PUMP}

\begin{abstract}
S u m m a r y
The paper present the expansion of heat pump market in Poland in years 2010-2013. The author carried out an analysis of the ground as the source of heat for heat pumps. The paper includes the presentation and comparison of different methods of selecting the pipe lengths for the heat exchanger which, according to the guidelines of PORT PC (Polish Organization Development and Technology of Heat Pump), is the ground heat source for heat pumps. It is followed by an algorithm for accurate calculation of heat flux rate and pipe length selection. The results are then compared with the previous ones. Estimating the amount of energy which could be gained from the ground is a complicated issue. In order to receive precise results, each type of ground the heat exchanger was placed in had to be examined. The kind of ground, which provides energy, is very important for design and selection of the ground heat source. The moisture content influences the ground thermal conductivity and the amount of absorbed energy. Guidelines about selecting the pipe lengths for vertical ground heat exchanger, published by PORT PC, can be used for initial and fast selection the pipe lengths. The obtained result has got some error in regard of presupposed value of heat flux. Recognition the kind of ground is important. Allows to carry out an accurate calculation of heat flux value gained from the ground, and select appropriate the pipe lengths regardless of implement method.
\end{abstract}

Keywords: ground heat source, heat pump brine/water, vertical ground heat exchanger

Przestano do redakcji: $18.02 .2015 \mathrm{r}$.

Przyjęto do druku: 22.06.2015 r.

DOI: $10.7862 / r b .2015 .47$ 